\title{
Raising Cross-Cultural Awareness Through Extensive Reading
}

\author{
Amalia Babayan \\ Yerevan State University \\ 1 Alex Manoogian st \\ Republic of Armenia
}

\begin{abstract}
The article discusses the inherent possibilities of an English reader, as a source of extensive reading material, for promoting cross-cultural awareness among readers, as well as boosting their oral communication skills, through incorporating the findings of area studies research into entertaining reading. It also examines different stages of book writing, focusing on creative tools and solutions that would enable an average material writer or author to succeed.
\end{abstract}

Keywords: cross-cultural awareness, communication, materials writing, area studies, English language teaching, extensive reading

\section{Introduction}

Reading is an essential part of language learning. Research has shown that students who read in English improve in every area of language competence at a faster rate than students who don't. (Teaching English/British Council 2012). They increase their vocabulary and become better writers as well as enhance their listening and speaking abilities (Day and Bamford 2002). Such an accelerated progress is often achieved due to the application of extensive reading approach when students embark in reading long texts or large quantities of information for understanding (Stanley 2013).

As different from intensive reading strategies, when the reading skill is often taught by a close and/or compulsory study of short passages followed by a detailed analysis of the language of the text (Stanley 2013), extensive reading opens up much wider possibilities to the students owing to its certain inherent features which intensive reading lacks.

In extensive reading, students read for the content of the text (Stanley 2013): it may be gaining new information or knowledge on a certain topic of interest, or broadening one's knowledge about issues never referred to or experienced before, or simply following the plot of a narrative that carries away with its developments and collisions, living through the emotions that are stirred up by the literary work, experiencing a sort of spiritual or artistic empathy, and, above all, encountering real, live language in its natural expressions. As N. Prentice states, 'extensive reading is real language in real use and demonstrates that books will always be the best and most stimulating teachers' (Prentice 2012).

Extensive reading is, by nature, a private, individual activity, undertaken away from the classroom (Gafurova 2018). It frees students from daily textbook routines (Prentice 2012) and gives freedom to read what, when, where and at whichever pace and mode they choose. In fact, it is a student-centered and student-managed activity. And in line with the concrete motivations of the student, it is mostly reading for pleasure, which is often mixed with the illuminating feeling of the joy of learning.

Another privilege of extensive reading is the diversity of the material it encompasses, for it is represented both by high literature, in the sense of classical and modern literary heritage, and literature in general - non-fiction publications, magazines, journals, the rich resources of the internet, etc. Literature engages the imagination of the readers (McRae 1991), their emotions, as well as their cognitive faculties (Pulverness 2003), it stimulates the processes of constructing meaning and deducing interpretations (Halliday 1989). It is, in fact, an endless horn of plenty that feeds and refines minds and souls through reading. The plethora of materials that extensive reading suggests allows students to read, read and read more (Day and Bamford 2002).

In extensive reading graded readers are designed so that they meet the requirements of the corresponding language level of the text, with a certain volume of grammatical structures and linguistic material familiar to the learners (Van Duzer 1999). Apart from it, a decisive aspect that creates the comfort zone for a successful language student is the cultural appropriacy of the reader in accordance with the age range, interests, sex and background culture of the learner, (Van Duzer 1999) being neither culturally dense nor offensive in its textual content (Pulverness 2003). So, literary texts for extensive reading often provide wide perspectives by fueling interest for cross-cultural exploration (Carter and McRae 1996) as well. 
As Kramsch states, literature lends itself well to investigating similarities and differences between self and others, to the understanding of others (Kramsch 1993), and 'expands the indispensable human capacity to read the world' (McRae 1991).

Being 'well-read of the world' has always been a signature feature of the intellectual elite of any society. But in the $21^{\text {st }}$ century charged with swift political, economic and cultural developments, people face even greater challenges of crosscultural character. Enhanced by the process of globalization and the unprecedented possibilities granted by technological advancement, people are being more and more involved in the goods and dangers which the extension and the intensity of these two engender. Therefore, nowadays the issue of being well-informed cross-culturally stands out as a necessity not only for a relatively small number of people - the elite, but for much larger sections of the society, those who vigorously traverse the world on myriad of engagements.

It is at these crossroads of cross-cultural knowledge acquisition and English language learning that extensive reading does set in as a wellspring of valuable information and insight. Giving credit to any kind of quality literature used for extensive reading, we should acknowledge the crucial fact that extensive reading can serve as one of the gateways to cross-cultural competence so important today. Being an entertaining, not binding reading, it can be used as a brilliant means for equipping students with practical knowledge for their future careers of foreign language and/or area studies specialists. The social requirement for this dual competence (language and area studies) is gaining more and more ground in the framework of promoting more beneficial civic and political ties.

Today, too, like in the past, many universities and educational institutions offer joint courses of language and area studies. A click on the mouse is the least we need to be notified about admission of students at the LLAS Centre for Languages, Linguistics and Area Studies at the University of Southampton or some other university. We can get informed of the national surveys conducted at nine universities in the UK in departments of languages, linguistics and area studies. We can read K. Koch's views on the practical approach to area studies and language teaching or learn that language and area studies training consultants are much wanted to train students, further to be enlisted in the US Intelligence Community. We can also find many Foreign Language and Area Studies Fellowships offered by different universities, etc.

So, it is evident that language learning and area studies go hand in hand, creating a natural alliance for mutually efficient implications.

\section{The Reader}

Taking advantage of the fact that extensive reading, so much needed for language learning, can provide a convenient framework for feeding in information from the field of area studies, we have come up with a new format of an English reader - one that blends into a mix the components of the literary narrative hewn to the canvas of the research in area studies, accompanied by language teaching assignments and exercises.

The idea to create a reader that would incorporate literary elements with language teaching tools based on findings of area studies research took shape and materialized under the programme Taiwan Fellowship (2014), which granted the opportunity to conduct research on certain aspects of Taiwanese area studies. Complemented by a similar study in Armenia, the book incorporated the findings of the research into a literary plot rounded off with language learning tasks and ideas.

1.1 The purpose of the reader is triple - to equip students with an easy-to-read extensive reading material, which will grab their interest both cognitively and emotionally, significantly expanding their knowledge about a given country, its history, traditions, cultural characteristics and current issues, and empower their English speaking as well as writing competence with targeted tasks which often call for creative thinking.

1.2 The objectives of the book are as follows: through a broad and intricate canvas of cross-cultural realia to secure intensive language input and practice, to kindle interest in certain area studies topics and problems, to build bridges for cross-cultural awareness, simultaneously tackling different language matters, as well as to invite individual research of students at definite points of the reading process.

1.3 The reader is intended for a certain type of audience (students of language courses and area studies or the like) and is designed to serve their interests or needs, though any such reader may as well be directed to the general audience.

Depending on the readers' language competence the language level is chosen accordingly.

Below we shall proceed with a discussion of the components of the process of the reader writing, conditionally grouping them under the subtitles 'Research', "The literary format', 'The language component', presenting them separately for the sake of analysis. However, we shouldn't dismiss the fact that in the book all these components are mingled, complementing and enriching one another. 
For the same reason stated above, the order of the components' interpretation is arbitrary. With different authors this order may change due to the individual writing styles of the persons writing the reader.

\section{Component I: Research}

We start with the component "Research", as it is the ground-forming base as well as the core material of the book and stands out as the most multifaceted time-and-work-consuming endeavor.

2.1 From the very beginning the scope and objectives of the research should be clearly defined. To create a literary or 'near-fiction' book with a definite bias towards area studies, one should distinctly realize the importance of the factual, scientific validity of the data-to-be-used in the narrative. So, the materials should be scrupulously chosen, studied and verified accordingly.

2.2 The motivational drive and guidance for the researcher should be the full awareness of the practical value of the future book in the promotion of cross-cultural contacts aimed at enhancing peaceful relations among people or favoring the solution of political concerns, the perception that by acquainting readers with the most eminent events about or related to the country and its people, he/she is breaking the ice of the bleak unawareness or void nonexistence of the topical issues in the readers' minds.

2.3 As to the scope of the required research, determined by the goals of the author, it can cover a wide range of aspects - from history, geography, ethnography, art and folklore to the latest political events or scientific advancements all making up the multicolored carpet-map of the nation's life.

2.4 A critical prerequisite is for the sources that the researcher studies and later uses in the book to be accurate, valid, authentic and upheld by the people the author is writing about, because side interpretations or explanations by foreigners or neighbors are quite often biased either because of the self-interest of the interpreting party, or because of the incomplete, one-sided perception of the matter.

It is evident that the best way of benefiting from authentic sources is being or living in the country you are going to speak about, experiencing the real life and conducting research there, using the immediate, on-the-spot resources available. This first-hand experience (as was in my case, for I had the chance to undertake my research both in Taiwan and Armenia), opens up plenty of opportunities for the researcher, including the expert opinions of native friends and colleagues, and secures the soundness and plausibility of the research outcome.

2.5 A point not to overlook in the exploration of the data is the special care for seemingly minute details, which are often essential, either for their scientific value, or for creating the meaningful emotional coloring of an appropriate setting or image or event in the book. In this respect folklore, the age-long wisdom of people, bears a significant load of national and cultural characteristics and can be implemented even in most unexpected contexts. Thus, estimating the scope and design of the research, we may state that the material-to-be-studied which will be suitable to feed the plot and the content of the book makes up a significant volume of work.

2.6 If, after the book has been completed, any significant material is left out that might be of help to the reader in his/her future work, a good solution is to enclose it in an Appendix as additional material for reference.

A quick recap of the 'Research' component concludes that it is a most laborious, demanding, painstakingly extensive scholarly work, the output of which is, as a rule, systematized and charted, time and again enriched and conveniently organized to be used in the future narrative.

\section{Component II: The Literary Format}

With a huge amount of research findings acquired and at hand, there comes the time for its literary embodiment, a time when one has to think over its literary shell - the format, the style, the plot filled with characters and developments, that could be dressed onto that rich fabric of the area studies tapestry. This is the time when imagination, creativeness, knowledge and skills of literary craft of the author paired with sober analytical mind comes in. The latter is of great importance, for the author cannot allow the excitement and inspiration of fiction-writing drift him/her away from the fact-based, accurately concrete reality of area studies.

3.1 Within the framework of this component the priorities to focus on are the storyline, the plot of the story with its climax and further developments, the suspense which urges the reader to read on and on and to the end, the characters and their relationships.In the case of our book it is a story of two individuals - a successful businessman and a high-ranking administrative officer, who build up their relationship through different stages of face-to-face and email encounters. They come to know each other speaking about their experiences, memories and projects, presenting their worlds to each other through the cultural, historical and political prisms of their homelands - the prisms and fabrics that are engrained in their personalities and eventually and invariably have shaped them. 
3.2 Depending on the storyline and characters and, certainly, on the author's preferences, the flow of events, the twists in the plot and the whole of the narrative are to be wrapped in the most appropriate literary genre, the one that will render best opportunities to proceed with the job of blending area studies material with the fiction elements.

For the book "From Taiwan with Love" the epistolary genre was chosen which duly justifies the storyline that is constructed around the plot when two people living in faraway countries converse predominantly through emails. Choosing this genre has also given us the chance to attach a supplement to each email - a sort of extension, that provides a more specific, versatile information on related topics. The material enclosed in the supplement, apart from being informative, presents a rich source for language practice, and gives ample ground for further deliberations. Apart from the above stated, the compact format of letter-writing not only implies a neat and accurate narrative but, owing to its communicative nature, may create space for digressions which bear elements of area studies information. Whereas with a dialogic text such deviations from the current flow of thoughts might be difficult or even impossible to wedge in.Our choice of the epistolary genre never suggests that it is the only genre to be used for this type of a reader. The choice of the genre exceptionally depends on the individual approach of the author, and we are more than sure that such books can be written in many other genres and styles such as detective or mystery stories, biographic novels, satirical books, adventure books or thrillers and even fantasies or fairy tales. Everything depends on the preferences, proficiency and mastery of the writer.

\section{Component III: The Language Component}

4.1 The target audience of the book is considered to be a decisive factor while contemplating the linguistic features of the narrative and the type of language to be used. The language competence level of the prospective audience in many ways determines the author's choice of the language of the narrative and that of characters. Many readers are either written or adapted or simplified to fit the A or B levels of the students' English language command, while a lot of books for extensive reading appeal to the students with $\mathrm{C}$ level competence.

4.2 However, when facing the challenge of the choice of the proper language level for this type of a reader, the content and the quality of the area studies material to be incorporated into the narrative, and the character of the topical issues to be covered are not least important factors. The inherent traits of the research output certainly leave their individual hallmark on the language options from which to choose. On average, it is more suitable to write a reader with a distinct undercurrent goal of area studies information inclusion at the B2 or C1 language competence level, though, in certain cases, it may also be downgraded to B1. The level indicator alone already specifies the scope of the linguistic wealth to be used - be it grammatical structures, phraseological units, elements of style or the vocabulary pick.

4.3 Another issue to consider is the language register, which is an accurate and sophisticated tool for the writer while creating the atmosphere of different settings, various subtle nuances and conveying concrete messages. The skillful use of the vast potential of the language register determines when and why the language register shift should occur, when should the author switch, for example, from formal to informal English or from standard English to colloquial language or jargon, etc.

Different options are dictated by the details of the storyline, the characters of the book and the main objectives of the author. However, a greater part of the area studies materials prompts us to follow a more neutral path of approach and language use, though, certainly, in special cases it might turn out to be otherwise, stipulated by the disposition and goals of the author.

In the book 'From Taiwan with Love", along with the development of the plot, the strictly official language of the characters is gradually modified into an everyday and amicable one, with flares of emotionally colored language at the end. So, a lot depends on the content of the text.

4.4 Another feature of the section 'The language component' is the language teaching aspect. As stated at the beginning of the article, one of the objectives of this type of a reader is the English language learning and language experiencing process, as is the case with readers generally. If in most readers we come across comprehension-checking exercises, this type of a reader has a vast possibility to offer tasks that enhance the oral skills of students. The content of the emails and their supplements (in the section 'Compound II' we spoke about the supplementary material that follows each email) form a favorable ground for numerous tasks that are aimed at developing oral communication and presentation skills. Out of forty plus different types of assignments we bring to your attention but a few. For example:

- Give your opinion concerning the motives lying on the background of the events described in the text.

- Role-play a brief conversation with your partner based on the facts in the text: Give a piece of good news -----React; Add more information ----Show surprise; Give an explanation -----Now you are doubtful; Give a strong argument ---- Give in. 
- Listen to Aram Khachaturian's 'Sabre Dance', 'Spartacus Suite' and 'Violin Concerto' and share your impressions with your colleagues. Think of ten adjectives that describe A. Khachaturian's music best.

- With your partner role-play a two-minute conversation about the topic discussed in the text. You are a representative of Taiwan's banking system, while your partner is an investor from the Middle East.

- Compare the information about the traditional Armenian family with that of the Taiwanese family. Note the common characteristic features, then speak about the differences.

- In pairs discuss the following: 1. Orchids and Taiwan's climate, 2. Exploring floral culture and industry in Taiwan, 3. Orchids in art and jewelry.

- Prepare a presentation on the monuments, architectural ensembles and remarkable sites of Yerevan. Include pictures and slides.

- Role-play the folk tale.

- Compare TUMO with a similar Taiwanese project for teenagers.

Such tasks and exercises not only brush up the communication and presentation skills of students but also invite them to plunge into different creative endeavors.

Apart from the assignments aimed at language competence development, a distinctive feature of this reader is the tasks which require further study or research of area studies issues related to the material already tackled above. For example:

- $\quad$ Describe the cross-strait relations between Taiwan and Mainland China before 2003.

- Find more information about the development of the present-day relations between Taiwan and Japan and share it with the group.

- Think of reasons why Qarahounj in Armenia and Stonehenge in England have historical similarities.

- Find out about ancient observatories of the world and name some of their common features.

- In groups talk about the following issues: a. The historical trail of the Chinese sword-fighting. b. Japanese swords, c. The revival of the art of Chinese sword-making.

\section{Conclusion}

As we can see, this mighty tool of language learning - extensive reading, when channeled from general to 'specialized' extensive reading, can be an excellent media for enhancing cross-cultural awareness and promoting area studies. We think that a new type of a reader for extensive reading, which blends the features of a literary work, area studies research and a host of assignments directed at elaborating students' language skills, can truly become a new trend in reader-writing among language teaching and area studies specialists, as it keeps in tune with the progress and issues of the contemporary life.Such readers can be created irrespective the peculiarities of the research material. They only require an average level of creativity and imagination, certain knowledge of literary craftsmanship, language teaching expertise and an abundance of material from area studies research.

\section{References}

Teaching English. 2012. Using Graded Readers. Teaching English/British Council/BBC. March 12, https://www.teachingenglish.org.uk

Day, R. and J. Bamford. 2002. Top ten principles for teaching extensive reading. In Reading in a Foreign Language 14/2. http://nflrc.hawaii-edu/rfl/October 2002/

Stanley, G. 2013. Language Learning with Technology. Cambridge University Press.

Prentice, N. 2012. What's the point of extensive reading? Oxford University Press, ELY, 1 November. https://oupeltglobalblog.com/2012/11/01/

Gafurova, N. 2018. The Importance of Usage of Extensive Reading.

https://internationalconference.ru./images/PDF/2018/39/

McRae, J. 1991. Literature with Small 'l'. London: McMillan Publishers Limited.

Pulverness, A. 2003. Literature. In English Teaching Professional, October, Issue 29. Modern English Publishing.

Halliday, M. 1989. Spoken and Written Language. Oxford: Oxford University Press.

Van Duzer. 1999. Theories of Reading 2. In Iranian Language Institute Language Teaching Journal. Volume 1.

Vethaman, M. 1996. Common Ground: Incorporating New Literatures in English in Language and Literature Teaching.

In Carter, R. and McRae, J. (eds.) Language, Literature and the Learner: Creative Classroom Practice. New York: Addison Wesley Longman.

Kramsch, C. 1993. Context and Culture in Language Teaching. Oxford: Oxford University Press. 